\title{
Novel Hepatitis B Virus Subgenotype in the Southern Yunnan Province of China
}

\author{
Tao Shen Jian-mei Gao Yun-Lian Zou Hong Dong Xin-Min Yan \\ Institute of Basic Medicine of the First People's Hospital of Yunnan Province, and Center of Clinical Molecular \\ Biology, and Kunhua Affiliated Hospital of Kunming Medical College, Kunming, PR China
}

\section{Key Words}

Hepatitis B virus · Genotypes • Subgenotypes •

Phylogenetic tree

\begin{abstract}
Hepatitis B virus (HBV) infection is highly prevalent in China. To identify the genotypes of HBV in the southern Yunnan Province of China, full-length HBV genomes were extracted from 1 Dai and 4 Hani HBV carriers and linked with the pMD T-18 vector. For each patient, 3-10 clones were sequenced directly and a consensus sequence was created. Genotypic and serotypic analysis revealed $4 \mathrm{HBV} / \mathrm{B}$ (2 B2 with adw2 and 2 new subgenotypes with ayw 1 ) and $1 \mathrm{HBV} / \mathrm{C}$ ( $\mathrm{C} 1$ with adrq + ) genotypes. The divergences of the entire genome sequences of the new subgenotype were $0-0.9 \%$ and $2.99-6.48 \%$ between other known HBV/B. Divergences in other coding regions revealed that it was more similar to $B 3$ and $B 4$ in the precore/core gene (2.02 and $2.09 \%$, respectively), and similar to $\mathrm{B} 3$ and $\mathrm{B} 5$ in the preS1/S2/S gene ( 2.24 and $2.78 \%$, respectively). Phylogenetic trees using the precore/core and $X$ genes both revealed a new clad separating from the major trunk of genotype B with a $99 \%$ bootstrap value. These results show that the 2 consensus isolates are a mosaic of $B 3-$ $\mathrm{B} 5$, which we designated to subgenotype B6. Considering the geographical distances, the relationship between $B 6$ and other HBV/B subgenotypes (B3-B5) and HBV evolution needs to be further studied.

Copyright $\odot 2009$ S. Karger AG, Basel
\end{abstract}

The hepatitis B virus (HBV) belongs to the genus Orthohepadnavirus of the Hepadnaviridae family. Based on $>8 \%$ intergenotype and $<4 \%$ intragenotype divergences, HBV has been classified into 8 different genotypes, named A-G [1-3]. Recently, a new genotype found in Laos and Vietnam has been defined as genotype I $[4,5]$. In addition, subgroups have been reported in different genotypes of HBV [3]. The genotypes of HBV have distinct geographical distributions [6, 7]. Some have been significantly associated with clinical patterns $[8,9]$, thus their detection and characterization are important for virus and disease surveillance.

Genotyping or subgenotyping can be accomplished based on full and partial sequences of HBV genome [10, 11]. Several methods have been developed and used for HBV genotyping including direct sequencing, restriction fragment length polymorphism [12], line probe assay, enzyme-linked immunoassay [13] and polymerase chain reaction (PCR) amplification using genotype-specific primers [14]. In this study, direct sequencing was used to determine the genotypes and subgenotypes of the isolates.

HBV infection is highly prevalent in China. A previous report demonstrated that genotypes $B$ and $C$ are the predominant ones in China. Other genotypes (A and D) and recombinants $(\mathrm{B} / \mathrm{C}$ and $\mathrm{C} / \mathrm{D})$ have also been found in China [15]. Yunnan is a province on the southwestern border of China, with the Tropic of Cancer running

\section{KARGER}

Fax +4161306 1234 E-Mail karger@karger.ch www.karger.com (c) 2009 S. Karger AG, Basel

$0300-5526 / 09 / 0526-0340 \$ 26.00 / 0$

Accessible online at:

www.karger.com/int
Xin-Min Yan

Institute of Basic Medicine of the First People's Hospital of Yunnan Province

No.157 Jin Bi Road

Kunming 650032, Yunnan Province (PR China)

Tel. +86871 363 8453, Fax +86 871364 8772, E-Mail Yxmin08@ 163.com 
through its southern part. It shares a border of $4,060 \mathrm{~km}$ with Burma in the west, Laos in the south and Vietnam in the southeast. The province is known to be one of the most ethnically diverse in China. Until recent times most of Yunnan was not easily reachable as it has been isolated from the outside world by precipitous mountains. To our knowledge, few data on HBV genotype distribution in these areas are available.

One Dai village and 2 isolated Hani villages, located in the mountains of Jihong, the capital of Xishuangbanna Dai Autonomous Prefecture of Yunnan province, were involved in this survey by the Institute of Basic Medicine, the First People's Hospital of Yunnan Province. All subjects included were indigenous inhabitants of Jinhong. Informed consent was obtained and 411 serum samples were collected. Forty-seven samples were positive for HBsAg. HBV DNA was extracted from these 47 serum samples with phenol-chloroform, precipitated with ethanol, and resuspended in Rnase-free water and stored at $-80^{\circ}$ until use. Full genomes of HBV DNA were amplified from 5 patients. The 5 patients were a 37-year-old female (M84), a 14-year-old male (M85), a 16-year-old female (M118), a 27-year-old male (L15) and a 16-year-old female (G67). The first 4 were native Hanis and the last one was a native Dai. All patients were negative for antibody against hepatitis $\mathrm{C}$ virus and human immunodeficiency virus and were not intravenous drug abusers. They were all positive for $\mathrm{HBsAg}, \mathrm{HBeAg}$ and $\mathrm{HBcAb}$ with high levels of HBV viral loads $\left(2.5 \times 10^{8}, 1.1 \times 10^{8}, 5.2\right.$ $\times 10^{8}, 2.3 \times 10^{8}$ and $1.4 \times 10^{8}$ copies $/ \mathrm{ml}$, respectively), and negative for anti-HBe.

The complete HBV genome was amplified by PCR with 2 primers as previously reported [16]. The PCR reaction was performed using the following cycles: $94^{\circ}$ predenatured for $5 \mathrm{~min}, 30$ cycles of $94^{\circ}$ for $1 \mathrm{~min}, 56^{\circ}$ for $1 \mathrm{~min}, 72^{\circ}$ for $2 \mathrm{~min}$ and $72^{\circ}$ for $10 \mathrm{~min}$ as a final extension step. Then full-length amplicons were purified using a gel extraction kit (HuaShun Bio-Engineering Co. Ltd.). The amplicons were linked with vector $\mathrm{pMD} 18$-T vector (TaKaRa Bio-Tech. Co. Ltd.) by using the standard cloning techniques. White colonies were picked; correct recombinants were confirmed by PCR and the double-restriction endonuclease digesting (EcoRI and Hind III). DNA sequencing analysis of the correct recombinants was performed with BigDye Terminator v3.1 and 3130 Genetic Analyzer (Applied Biosystems). For each patient, 3-10 recombinants were stochastically selected to be sequenced.

The whole genome sequences were assembled from sequencing data and were registered with GenBank un- der the accession numbers M84 (EU330988-91), M85 (EU330992-1001), M118 (EU305546-48), L15 (EU30554345) and G67 (EU305540-42, EU330986). For each patient, a consensus sequence was created by using the BioEdit software, version 7.0.5.2 [17], named as consensus M84, M85, M118, L15 and G67, respectively. Alignment was performed with Clustal X software, version 1.83 [18]. Phylogenetic tree analysis was carried out with MEGA software version 3.1 [19], using the neighbor-joining method, with 1,000 bootstrapped data sets. Genetic distance calculation and pairwise distance comparisons were performed with the Kimura 2-parameter model integrated into the MEGA software.

To identify the genotypes and subgenotypes, the consensus sequences of each patient were compared with 9 reported HBV genotypes (A-I) by using the full-length nucleotide sequences. Representative isolates of genotypes/subgenotypes A-I were retrieved from DDBJ/GenBank. The accession numbers and countries of origin are: AY128092 (Ae, Canada); M57663 (Aa, Philippines); D23679, D00329, AB073858 (B1, Japan); AF282917, AB073840 (B2, China); D00331, AB033554, AB033555, M54923 (B3, Indonesia); AB219430 (B3, Philippines); AB073835, AB031266 (B4, Vietnam); AB219426-29, AB241116-17 (B5, Philippines); AY217376 (C1, China); AF068756 (C1, Thailand); AF233236, Y18857 (C2, China); X04615 (C2, Japan); X75655-56 (C3, Polynesia); AB048704-5 (C4, Australia); AB241110, AB241112-13 (C5, Philippines); AB119256 (D, Japan); AY945307 (D, India); AB205192 (E, Ghana); AP007262 (E, Japan); AY090455 (F, Nicaragua), AB036915 (F, Indonesia); AB056514 (G, USA); AP007264 (G, Japan); FJ023670, FJ023675, FJ23659 (I, Laos); and AB232908 (I, Vietnam).

The results of intergroup divergences of entire genome sequences revealed that these 5 consensus sequences were genotypes B (M84, M85, M118 and L15; 4.16-4.31\% with $\mathrm{HBV} / \mathrm{B})$ and $\mathrm{C}(\mathrm{G} 67 ; 5.45 \%$ with HBV/C). Among the present 5 consensus sequences, 1 isolate belonged to subgenotype $\mathrm{C} 1$ (G67), 2 isolates belonged to subgenotype $\mathrm{B} 2$ (M118 and L15), and the other 2 (M84 and M85) were very similar to the subgenotype B3. We proposed that these 2 consensus isolates belong to a new HBV/B subgenotype, which we designated as B6.

Further analyses showed that the intragroup divergence of the entire genome sequences of B6 was $0-0.9 \%$. The intergroup nucleotide divergences over the complete genome sequences between $\mathrm{B} 6$ and the other subgenotypes were [mean $\pm \mathrm{SD}$ (range)] $6.48 \pm 0.39 \%$ with Japan (B1), $5.01 \pm 0.38 \%$ with China (B2), $2.99 \pm 0.28 \%$ 
Table 1. Mean percentage of nucleotide divergence over the entire genome and coding regions among $\mathrm{HBV} / \mathrm{B}$ and $\mathrm{HBV} / \mathrm{C}$ isolates

\begin{tabular}{|c|c|c|c|c|c|c|c|c|c|c|}
\hline Full-length & B1 & B2 & B3 & B4 & B5 & $\mathrm{C} 1$ & $\mathrm{C} 2$ & $\mathrm{C} 3$ & $\mathrm{C} 4$ & C5 \\
\hline B6 & $6.48 \pm 0.39$ & $5.01 \pm 0.38$ & $2.99 \pm 0.28$ & $4.49 \pm 0.36$ & $3.57 \pm 0.30$ & $8.61 \pm 0.50$ & $8.29 \pm 0.53$ & $8.89 \pm 0.55$ & $9.83 \pm 0.50$ & $9.57 \pm 0.57$ \\
\hline B1 & - & $4.51 \pm 0.37$ & $6.17 \pm 0.36$ & $4.91 \pm 0.36$ & $6.17 \pm 0.38$ & & & & & \\
\hline B2 & & - & $4.86 \pm 0.32$ & $3.75 \pm 0.34$ & $4.86 \pm 0.36$ & & & & & \\
\hline B3 & & & - & $4.56 \pm 0.31$ & $3.61 \pm 0.26$ & & & & & \\
\hline B4 & & & & - & $4.80 \pm 0.37$ & & & & & \\
\hline \multicolumn{11}{|l|}{ Sgene } \\
\hline B6 & $1.71 \pm 0.42$ & $1.21 \pm 0.38$ & $0.63 \pm 0.23$ & $1.05 \pm 0.31$ & $1.29 \pm 0.35$ & $6.25 \pm 1.00$ & $6.29 \pm 1.03$ & $6.65 \pm 0.99$ & $6.06 \pm 0.90$ & $6.06 \pm 0.88$ \\
\hline B1 & - & $1.39 \pm 0.36$ & $1.57 \pm 0.39$ & $1.84 \pm 0.42$ & $2.39 \pm 0.47$ & & & & & \\
\hline B2 & & - & $1.13 \pm 0.34$ & $1.79 \pm 0.44$ & $2.09 \pm 0.47$ & & & & & \\
\hline B3 & & & - & $1.31 \pm 0.32$ & $1.70 \pm 0.38$ & & & & & \\
\hline B4 & & & & - & $1.94 \pm 0.41$ & & & & & \\
\hline \multicolumn{11}{|l|}{ pres1 gene } \\
\hline B6 & $8.29 \pm 1.48$ & $8.04 \pm 1.51$ & $4.48 \pm 1.09$ & $8.84 \pm 1.60$ & $4.93 \pm 1.06$ & $16.12 \pm 2.19$ & $13.82 \pm 1.94$ & $15.07 \pm 2.13$ & $17.08 \pm 2.36$ & $17.66 \pm 2.36$ \\
\hline B3 & & & - & $8.36 \pm 1.55$ & $4.22 \pm 0.94$ & & & & & \\
\hline \multicolumn{11}{|l|}{ preS2 gene } \\
\hline B6 & $7.40 \pm 2.10$ & $5.73 \pm 1.98$ & $4.15 \pm 1.56$ & $6.58 \pm 2.00$ & $4.82 \pm 1.35$ & $13.48 \pm 2.97$ & $14.03 \pm 3.13$ & $17.04 \pm 3.51$ & $15.94 \pm 3.39$ & $11.76 \pm 2.90$ \\
\hline B3 & & & - & $7.02 \pm 1.94$ & $4.18 \pm 1.11$ & & & & & \\
\hline \multicolumn{11}{|c|}{ pres1/S2 gene } \\
\hline B6 & $8.13 \pm 1.42$ & $7.78 \pm 1.45$ & $4.35 \pm 1.05$ & $8.70 \pm 1.58$ & $4.93 \pm 1.08$ & $15.75 \pm 2.16$ & $13.37 \pm 1.94$ & $14.57 \pm 2.12$ & $16.48 \pm 2.23$ & $17.07 \pm 2.26$ \\
\hline B3 & & & - & $8.23 \pm 1.56$ & $4.24 \pm 0.92$ & & & & & \\
\hline \multicolumn{11}{|c|}{ preS1/S2/S gene } \\
\hline B6 & $4.39 \pm 0.57$ & $3.80 \pm 0.54$ & $2.24 \pm 0.40$ & $3.93 \pm 0.49$ & $2.78 \pm 0.43$ & $10.06 \pm 0.94$ & $9.51 \pm 0.88$ & $10.47 \pm 0.98$ & $10.46 \pm 0.98$ & $10.12 \pm 0.91$ \\
\hline B2 & & - & $3.55 \pm 0.51$ & $2.47 \pm 0.42$ & $4.11 \pm 0.52$ & & & & & \\
\hline B3 & & & - & $3.99 \pm 0.53$ & $2.70 \pm 0.37$ & & & & & \\
\hline B4 & & & & - & $4.52 \pm 0.51$ & & & & & \\
\hline \multicolumn{11}{|l|}{ X gene } \\
\hline B6 & $4.12 \pm 0.89$ & $4.61 \pm 0.94$ & $3.80 \pm 0.75$ & $3.00 \pm 0.73$ & $4.04 \pm 0.88$ & $6.33 \pm 1.12$ & $6.35 \pm 0.91$ & $7.92 \pm 1.33$ & $7.56 \pm 1.26$ & $7.76 \pm 1.24$ \\
\hline B3 & & & - & $3.31 \pm 0.63$ & $3.84 \pm 0.67$ & & & & & \\
\hline B4 & & & & - & $2.82 \pm 0.62$ & & & & & \\
\hline \multicolumn{11}{|l|}{ Pgene } \\
\hline B6 & $5.59 \pm 0.43$ & $5.25 \pm 0.47$ & $3.03 \pm 0.31$ & $4.92 \pm 0.45$ & $3.61 \pm 0.36$ & $9.43 \pm 0.64$ & $9.24 \pm 0.64$ & $9.55 \pm 0.65$ & $10.68 \pm 0.68$ & $10.32 \pm 0.75$ \\
\hline B3 & & & - & $5.08 \pm 0.41$ & $3.70 \pm 0.31$ & & & & & \\
\hline B4 & & & & - & $5.23 \pm 0.43$ & & & & & \\
\hline \multicolumn{11}{|c|}{ preC/C gene } \\
\hline B6 & $9.25 \pm 1.13$ & $2.42 \pm 0.54$ & $2.02 \pm 0.50$ & $2.09 \pm 0.51$ & $2.43 \pm 0.52$ & $3.16 \pm 0.65$ & $2.21 \pm 0.52$ & $4.17 \pm 0.81$ & $4.34 \pm 0.79$ & $3.43 \pm 0.68$ \\
\hline B1 & - & $9.32 \pm 1.11$ & $9.75 \pm 1.16$ & $9.86 \pm 1.15$ & $10.32 \pm 1.18$ & $9.95 \pm 1.19$ & $9.42 \pm 1.15$ & & & \\
\hline B2 & & - & $2.94 \pm 0.11$ & $2.83 \pm 0.55$ & $2.95 \pm 0.54$ & $3.94 \pm 0.71$ & $2.86 \pm 0.57$ & & & \\
\hline B3 & & & - & $2.08 \pm 0.56$ & $2.77 \pm 0.45$ & $3.58 \pm 0.66$ & $2.63 \pm 0.54$ & & & \\
\hline B4 & & & & - & $2.82 \pm 0.55$ & $3.53 \pm 0.65$ & $2.53 \pm 0.54$ & & & \\
\hline B5 & & & & & - & $4.19 \pm 0.72$ & $3.41 \pm 0.66$ & & & \\
\hline $\mathrm{C} 1$ & & & & & & - & $1.87 \pm 0.38$ & & & \\
\hline \multicolumn{11}{|c|}{ Core gene } \\
\hline B6 & $10.28 \pm 1.29$ & $2.81 \pm 0.64$ & $2.31 \pm 0.59$ & $2.14 \pm 0.57$ & $2.64 \pm 0.60$ & $3.67 \pm 0.76$ & $2.41 \pm 0.60$ & $4.86 \pm 0.94$ & $4.65 \pm 0.89$ & $4.08 \pm 0.81$ \\
\hline B1 & - & $10.35 \pm 1.24$ & $10.81 \pm 1.29$ & $10.58 \pm 1.31$ & $11.35 \pm 1.31$ & $11.09 \pm 1.35$ & $10.52 \pm 1.31$ & & & \\
\hline B2 & & - & $3.38 \pm 0.63$ & $3.01 \pm 0.64$ & $3.24 \pm 0.60$ & $4.59 \pm 0.82$ & $3.17 \pm 0.65$ & & & \\
\hline B3 & & & - & $2.10 \pm 0.47$ & $2.99 \pm 0.54$ & $4.12 \pm 0.74$ & $2.87 \pm 0.60$ & & & \\
\hline B4 & & & & - & $2.87 \pm 0.55$ & $3.81 \pm 0.71$ & $2.48 \pm 0.55$ & & & \\
\hline B5 & & & & & - & $4.67 \pm 0.79$ & $3.61 \pm 0.69$ & & & \\
\hline $\mathrm{C} 1$ & & & & & & - & $2.01 \pm 0.76$ & & & \\
\hline
\end{tabular}

Low divergences are shown in bold. Intrasubgroup divergences of $\mathrm{HBV} / \mathrm{B}$ and $\mathrm{HBV} / \mathrm{C}$ are shown only in those with lower divergences to B6. Subgenotypes B1-B5 and C1-C5 are grouped isolates of representative subgenotypes. B6: the consensus sequence of all the M85 and M84 isolates. 
Fig. 1. Phylogenetic tree of the precore/ core gene constructed by the neighborjoining method using the present 5 consensus sequences and other genotype isolates retrieved from DDBJ/GenBank. Bootstrap values are indicated for each group. The length of the horizontal bar indicates the number of nucleotide substitutions per site. The 5 consensus sequences presented in this study are shown in bold. Each consensus sequence was created using all the clones from each patient.

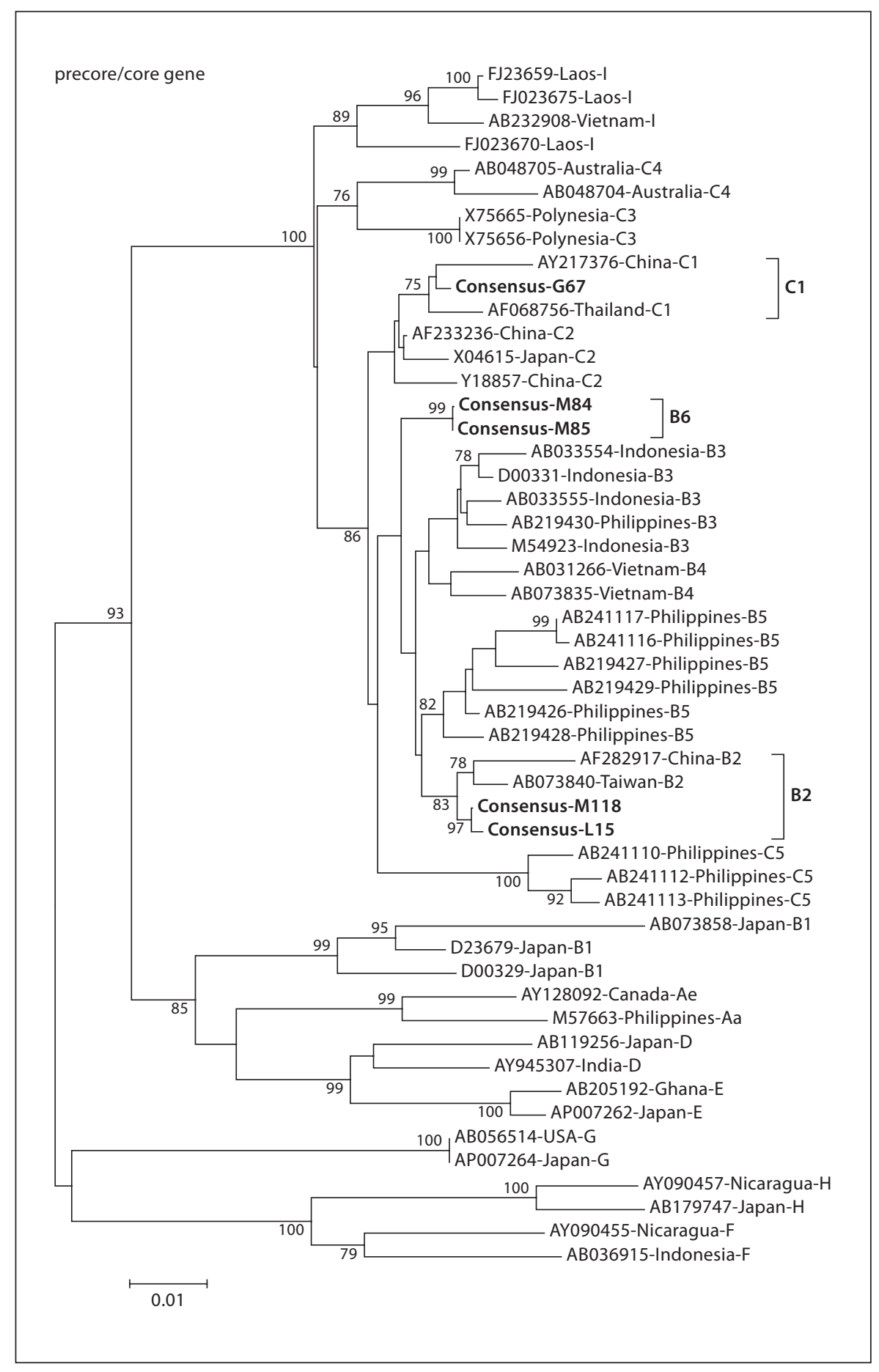

with Indonesia and the Philippines (B3), $4.49 \pm 0.36 \%$ with Vietnam (B4) and $3.57 \pm 0.30 \%$ with the Philippines (B5). These data showed that the newly identified subgenotype B6 is close to subgenotype B3. Interestingly, among the grouped subgenotypes of B1-B5, B3 showed the lowest divergences with the grouped HBV/B (B1, B2, B4 and B5): $6.17 \pm 0.36 \%$ with Japan (B1), $4.86 \pm 0.32 \%$ with China (B2), $4.56 \pm 0.31 \%$ with Vietnam (B4), 3.61 $\pm 0.26 \%$ with the Philippines (B5), and the intragroup divergence of $\mathrm{B} 3$ was $1.68 \pm 0.17 \%$ (table 1 ). 
Fig. 2. Phylogenetic tree of the X gene constructed by the neighbor-joining method using the present 5 consensus sequences and other genotype isolates retrieved from DDBJ/GenBank. Bootstrap values are indicated for each group. The length of the horizontal bar indicates the number of nucleotide substitutions per site. The 5 consensus sequences presented in this study are shown in bold. Each consensus sequence was created using all the clones from each patient.

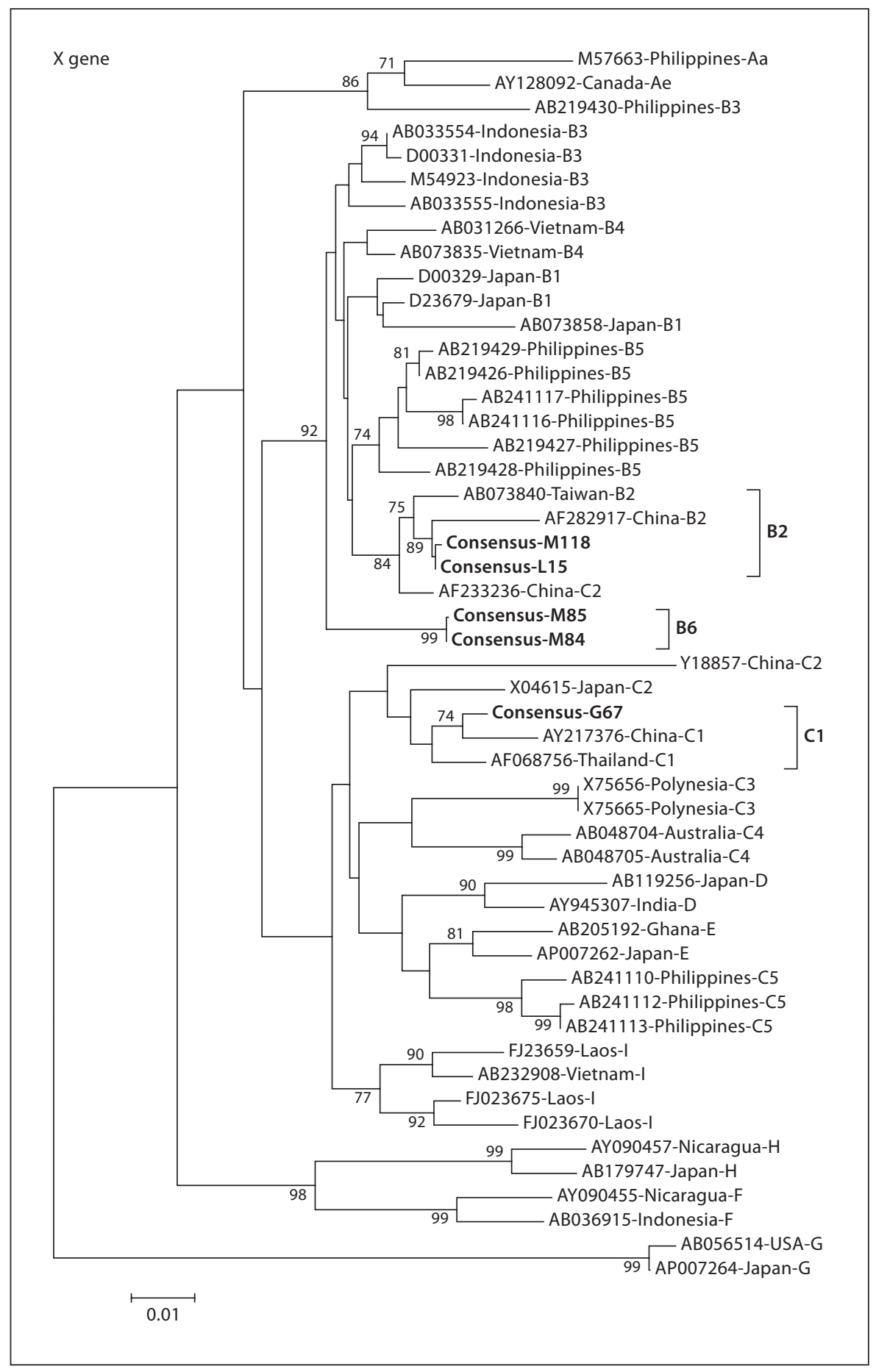

In addition, comparing precore and core genes revealed that, like in $\mathrm{B} 2-\mathrm{B} 5, \mathrm{~B} 6$ had recombined with $\mathrm{HBV} / \mathrm{C}$ in the precore and core genes $(3.35 \pm 0.53 \%$ vs. $3.82 \pm 0.61 \%$, respectively) but differed at least $5 \%$ from other genotypes (online supplementary table 1 , www.karger.com/doi/10.1159/000252912. Through the construction of a phylogenetic tree by using the precore/ core gene and $\mathrm{X}$ gene, respectively, it was revealed that there is a new clad separating from the major trunk of genotype B with a $99 \%$ bootstrap value (fig. 1 and 2). 
Pairwise comparisons between B6 and grouped subgenotypes $\mathrm{B} 1-\mathrm{B} 5$ and $\mathrm{C} 1-\mathrm{C} 5$ by using different regions of HBV revealed that in the case of the $\mathrm{P}$ gene, this group is more closely related to subgenotypes B3 and B4 (3.03 vs. 3.61\%) with a $100 \%$ bootstrap value. In the case of the preS1/S2 gene, this group is more closely related to the subgenotypes B3 and B5 (4.35 vs. 4.93\%) with a $99 \%$ bootstrap value. In the case of the preS1 gene, this group is more strongly linked with the subgenotypes B3 and B5 ( 4.48 vs. $4.93 \%)$ with a $100 \%$ bootstrap value. On the other hand, the $S$ gene was more closely related to the subgenotype B3 $(0.63 \%)$ with a $71 \%$ bootstrap value (online suppl. fig. 1A-E).

Based on the Arg/Lys ${ }^{120}$, Lys/Arg ${ }^{160}, \operatorname{Pro}^{127}, \mathrm{Val}^{177}$ and Pro $^{178}$ within the $S$ gene [20], the serotypes of the consensus isolates of this report were found to be aywl (M84 and M85), adw2 (M118 and L15) and adrq+ (G67), respectively.

In conclusion, we propose that the 2 isolates from a Hani village of the Xishuangbanna Dai Autonomous Prefecture in Yunnan province, China, is a new recombinant of $\mathrm{HBV} / \mathrm{B}$, for the following reasons. The divergences between these new Hani isolates and the other 5 subgenotypes were $2.99-6.48 \%$, which is within the previously reported range of divergence between any 2 subgenotypes $(2.9-6.80 \%$ or $2.9-6.1 \%)[6,11]$. In addition, sig- nificant bootstrap values were confirmed on the phylogenetic tree analysis of the complete and partial nucleotide sequences. Thirdly, the serotype of $\mathrm{B} 3$ was found to be adw, B4 and B5 were ayw, and these new Hani isolates were also ayw. Furthermore, their X and polymerase gene encoded distinctive conserved amino acids such as $\mathrm{Thr}^{34}$, Ile/Thr ${ }^{98}$, Met ${ }^{105}$ (X gene) and $\mathrm{Glu}^{187}, \mathrm{Pro}^{205}, \mathrm{Try}^{231}$, $\mathrm{Ala}^{298}, \mathrm{Lys}^{315}$ and $\mathrm{Val}^{346}$ (P gene), respectively, which did not belong to subgenotypes B1-B5.

To our knowledge, this is the first report of the entire nucleotide sequences of HBV/B from the indigenous Hani and Dai peoples from isolated villages. The Xishuangbanna Dai Autonomous Prefecture is adjacent to Vietnam and Laos, and also close to Indonesia and the Philippines. Through phylogenetic analysis, these new isolates showed a mosaic characteristic of subgenotypes B3-B5. The evolution value of this variant needs to be further explored in further studies.

\section{Acknowledgements}

This study was supported by the Natural Science Foundation of Yunnan Province (grant No. 200300172), P.R. China, and part by the Hospital Science Foundation of the First People's Hospital of Yunnan Province $(2004,2007)$.

\section{References}

1 Okamoto H, Tsuda F, Sakugawa H, Sastrosoewignjo RI, Imai M, Miyakawa Y, Mayumi $\mathrm{M}$ : Typing hepatitis B virus by homology in nucleotide sequence: comparison of surface antigen subtypes. J Gen Virol 1988;69:25752583.

-2 Kurbanov F, Tanaka Y, Fujiwara K, Sugauchi F, Mbanya D, Zekeng L, Ndembi N, Ngansop C, Kaptue L, Miura T, Ido E, Hayami M, Ichimura $\mathrm{H}$, Mizokami M: A new subtype (subgenotype) Ac (A3) of hepatitis B virus and recombination between genotype $A$ and E in Cameroon. J Gen Virol 2005;86:20472056.

-3 Schaefer S: Hepatitis B virus taxonomy and hepatitis B virus genotypes. World J Gastroenterol 2007;13:14-21.

$\checkmark 4$ Olinger CM, Jutavijittum P, Hübschen JM, Yousukh A, Samountry B, Thammavong T, Toriyama K, Muller CP: Possible new hepatitis B virus genotype, Southeast Asia. Emerg Infect Dis 2008; 14:1777-1779.

$\checkmark 5$ Tran TT, Trinh TN, Abe K: New complex recombinant genotype of hepatitis $\mathrm{B}$ virus identified in Vietnam. J Virol 2008;82:56575663.

New Subgenotype of HBV in

Southwestern China
-6 Liu WC, Phiet PH, Chiang TY, Sun KT, Hung $\mathrm{KH}$, Young KC, Wu IC, Cheng PN, Chang TT: Five subgenotypes of hepatitis B virus genotype $\mathrm{B}$ with distict geographic and virological characteristics. Virus Res 2007;129: 212-223.

7 Norder H, Courouce AM, Coursaget P, Echevarria JM, Lee SD, Mushahwar IK, Robertson BH, Locarnini S, Magnius LO: Genetic diversity of hepatitis B virus strains derived worldwide: genotypes, subgenotype, and HBsAg subtypes. Intervirology 2004; 47: 289-309.

$\checkmark 8$ Hasegawa I, Tanaka Y, Kramvis A, Kato T, Sugauchi F, Acharya SK, Orito E, Ueda R Kew MC, Mizokami M: Novel hepatitis B virus genotype a subtyping assay that distinguishes subtype Aa from Ae and its application in epidemiological studies. J Virol 2004; 78:7575-7581. $\checkmark 9$ Sugauchi F, Orito E, Ichida T, Kato H, Sakugawa H, Kakumu S, Ishida T, Chutaputti A, Lai CL, Ueda R, Miyakawa Y, Mizokami $\mathrm{M}$ : Hepatitis $\mathrm{B}$ virus of genotype $\mathrm{B}$ with or without recombination with genotype $\mathrm{C}$ over the precore region plus the core gene. J Virol 2002;76:5985-5992.

10 Ohba K, Mizokami M, Ohno T, Orito E, Lau JY, Ina Y, Ikeo K, Gojobori T: Relationship between serotypes and genotypes of hepatitis B virus genetic classification of $\mathrm{HBV}$ by use of surface genes. Virus Res 1995;39:2534.

11 Nagasaki F, Niitsuma H, Cervantes JG, Chiba M, Hong S, Ojima T, Ueno Y, Bondoc E, Kobayashi K, Ishii M, Shimosegawa T: Analysis of the entire nucleotide sequence of hepatitis $\mathrm{B}$ virus genotype $\mathrm{B}$ in the Philippines reveals a new subgenotype of genotype $B$. J Gen Virol 2006;87:1175-1180.

-12 Mizokami M, Nakano T, Orito E, Tanaka Y, Sakugawa H, Mukaide M: Hepatitis B virus genotype assignment using restriction fragment length polymorphism patterns. FEBS Lett 1999;450:66-71. 
-13 Usuda S, Okamoto H, Iwanari H, Baba K, Tsuda F, Miyakawa Y, Mayumi M: Serological detection of hepatitis B virus genotype by ELISA with monoclonal antibodies to typespecific epitomes in the preS2-region product. J Virol Methods 1999;80:97-112.

14 Zumbika E, Ruan B, Xu CH, Ni Q, Hou W, Chen Z, Liu KZ: HBV genotype characterization and distribution in patients with HBV-related liver diseases in Zhejiang Province, P.R. China: possible association of coinfection with disease $\mathrm{p}$ prevalence and severity. Hepatobiliary Pancreat Dis Int 2005; 4:5352-5431.
5 Wang AH, Liu ZH, Zeng GB, Wen SJ, Qi YP, Ma SW, Naoumov NV, Hou JL: A new intertype recombinant between genotypes $\mathrm{C}$ and $\mathrm{D}$ of hepatitis B virus identified in China. J Gen Virol 2005;86:985-990.

16 Shen T, Yan YM, Zou YL, Gao JM, Dong H: Virologic characteristics of hepatitis B virus in patients infected via maternal-fetal transmission. World J Gastroenterol 2008; 14 5674-5682.

17 Hall TA: Benedict: a user-friendly biological sequence alignment editor and analysis program for Windows 95/98/NT. Nucleic Acids Symp Ser 1999;41:95-98.
18 Thompson JD, Gibson TJ, Plewniak F, Jeanmougin F, Higgins DG: The CLUSTAL X windows interface: flexible strategies for multiple sequence alignment aided by quality analysis tools. Nucleic Acids Res 1997;25: 4876-4882.

19 Kumar S, Tamura K, Nei M: MEGA3: integrated software for molecular evolutionary genetics analysis and sequence alignment. Brief Bioinform 2004;5:150-163.

20 Margeridon S, Lachaux A, Trepo C, Zoulim F, Kay A: A quasi-monoclonal anti-HBs response can lead to immune escape of 'wildtype' hepatitis B virus. J Gen Virol 2005;86: 1687-1693. 